\title{
Chatter Behavior in the Milling Process of Inconel 718: Effects of Tool Edge Radius
}

\author{
Hoe C H, Reddy M M , Lee V C C and Debnath S \\ Curtin University Malaysia, CDT 250, 98009 Miri, Sarawak, Malaysia \\ mohan.m@curtin.edu.my
}

\begin{abstract}
Inconel 718 is widely used in various high end industries such as aerospace, nuclear plant, petrochemical plants etc. Inconel 718 is used for these applications due to unique mechanical properties such as high mechanical strength at elevated temperatures, high resistance to corrosion, and high strength to weight ratio. The unique properties of Inconel 718 made it difficult to be machined due to rapid work hardening and high cutting temperature. In addition, chatter vibration further increases the difficulty in machining of Inconel 718. In this paper, an experimental study on the effects of tool edge radius to the chatter behaviour was investigated. The dynamic responses of the milling process were recorded and analysed in both time domain and frequency domain. The results showed the variable helix and pitch end mill tool with larger tool edge radius able to mitigate chatter vibration at lower cutting speeds. Variable helix and pitch end mill with specific tool edge radius able to mitigate chatter vibration under the same cutting parameters. Experiments shows proper selection of tool edge radius improves the stability of end milling machining process.
\end{abstract}

\section{Introduction}

Inconel 718 is one of the Nickel based super alloys that are widely used in the various industries such as aerospace, nuclear, petrochemical plants, food processing equipment and etc [1-3]. Inconel 718 is famous in high temperature application owning to its outstanding properties such as able to maintain high mechanical strength at elevated temperature, high resistance to chemical wear, high resistance to corrosion as well as high strength to weight ratio [4]. However, Inconel 718 is extremely difficult to machine. In fact, Inconel 718 as one of the lowest machinability rating compared to other alloys [5]. Moreover, the combination of hightemperature mechanical properties, poor thermal properties (low thermal conductivity and thermal diffusivity) and rapid work hardening are the main factors that classified Inconel 718 as difficult-to-cut material [6]. As a result, high cutting temperature is generated at the cutting zone during the machining process of Inconel 718. Many researchers have carried out various studies to enhance the machinability of Inconel 718 by adapting different kind of cutting tools (coating, geometry and tool material) with different combination of cutting parameters and different cutting conditions [6-9]. For example, Jawaid [6] study the cutting performance and wear characteristic of coated and uncoated cutting tool in the face milling process of Inconel 718. The research shows that the coated tool has a better performance compared to the uncoated tool. Zhang [7] estimate the tool life and measure the cutting force in the end milling process of Inconel 718 under dry and minimum quantity cooling bio-lubrication condition. It is found that the tool life increases and has lower cutting force when the milling process is carry out under minimum quantity lubrication process. Hadi [8] compared the up and down milling process of Inconel 718 under different cutting condition, author found that the propagation of tool wear in up milling is more significant than down milling process. Although much effort has been work on to improve the machinability of Inconel 718, however, the chatter vibrations that develop during the machining process of Inconel 718 are rarely discussed in most of the studies regarding the machining process of Inconel 718.

Chatter vibration that caused by self-excited vibration is the most undesirable and the least controllable vibration. Taylor [10] described the chatter vibration is the "most obscure and delicate of all problems facing machinist". The self-excited vibration that occur in metal cutting are mainly due to the regenerative effect, the waviness of the surface that caused by the overlapping cutting process will further amplify the vibration and therefore, chatter vibration occurs [11,12]. Quintana [13] describe the adverse effect inflicted by chatter vibration 
can be devastating and therefore resulting in poor surface quality, machine tool damage, pre-mature tool wear, waste of energy, waste of material, and increase in production cost in term of production time, rapid tool wear. In order to avoid chatter vibration in the machining process, one of the methods is to generate the stability lobe diagram. The first stability lobe diagram was proposed by Tobias and Fiswick [14] for the turning process, stability lobe diagram is used to define the stable machining region (i.e no chatter) and the unstable machining region (i.e with chatter) as a function of axial depth of cut and spindle speed. The typical stability lobe diagram can be visualized in Figure 1 which formed by a series of intersected scallop-shaped lobe, the stable machining region is the area below the lobe while the unstable machining region is the area above the lobe. By selecting the machining parameters under the stability lobe can greatly improve the productivity of the machining process. In addition, the area on the left hand side of the stability lobe diagram is defined as the process damping region. The process damping only occur at low spindle speed, the damping phenomena occur at the contact between tool flank and the machined surface that will result in mitigation of chatter vibration [15]. However, the calculation of stability lobe diagram are difficult and lengthy process due to the modeling process of the multi-degree-freedom structures, there is a lot of parameters need to be considered in the development of stability lobe diagram such as the frequency response function of machine-tool, geometry of cutting tool, work piece material properties, radial immersion rate and so on. In addition, every stability lobe diagram is only unique for a specific process setup, the stability lobe need to be developed again if any of the parameters changes.

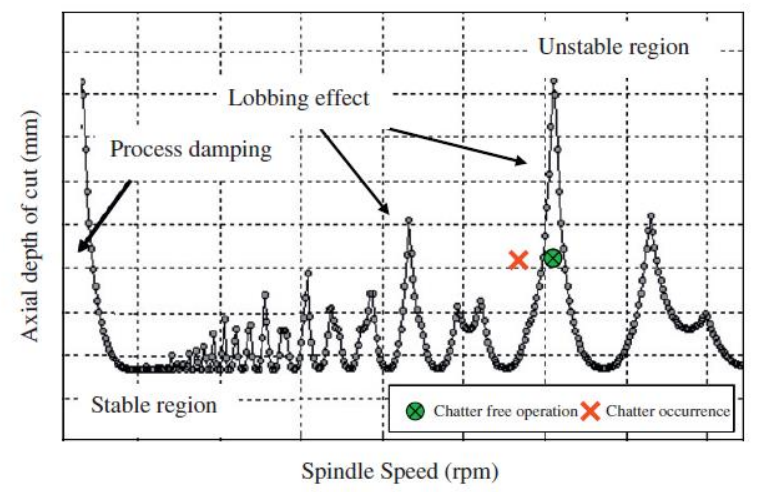

Figure 1 Stability lobe diagram [13]

Besides adapting stability lobe to avoid chatter vibration, another way to mitigate chatter vibration will be the use of variable helix and pitch end mill cutters which is first proposed by Slavicek [16]. The variable helix and pitch feature are designed to address the regenerative effect in the milling process by shifting the buildup of the chatter vibration. In other word, the regenerative effect is interrupted by the geometry of the cutting tool (ie. variable helix and pitch). Shirase [17] further shows that the variable helix and pitch end mill cutters able to reduce dimensional form errors as well as mitigate chatter vibration via experiment and simulation method. After that, Altintas [18] present an analytical model in predicting the stability lobes for variable pitch end mill cutters and the study demonstrated that variable pitch able to eliminate chatter vibration. In short, Literatures show that the variable pitch and helix end mill are capable to interrupt the dynamic system in the milling process and therefore increase the stability of the process [19-21]. Huang [19] observed lower vibration generated by variable pitch tool in the milling process of titanium alloy. Currently variable pitch and helix end mill cutters are available in the industrial environment. However, the use of variable pitch and helix end mill cutters is still not very extensive; this might due to the lack of knowledge about the cutters ability as well as its reliability. In addition, the variable helix and pitch end mills in the market now also available with multiple selection of tool edge radius. Study on the performance of the variable helix and pitch end mill cutters with tool edge radius end mill is limited.

The geometry of cutting tool edge play an important role in the machining process because the mechanical and thermal loads are directly sustain by cutting tool edge during the machining process [22]. Moreover, the tool life and the machined surface quality are affected by the shape of the cutting tool edge. There are three kind of cutting tool edge in general, namely (sharp, round and chamfer) and it is normally found in cutting tool with inserts. Endres [23] studied the effect of tool edge on the cutting tool flank wear in the turning process. The study concluded that there is a clear reduction of tool wear with the use of radius edge compare to the sharp edge as shown in Figure 2.

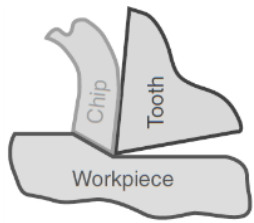

(a)

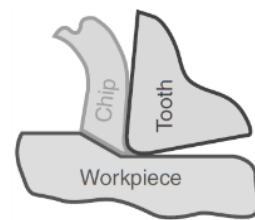

(b)
Figure 2 Illustration of tool edge (a) Sharp tool (b) Radius edge

Therefore, one might hypothesize that the tool edge geometry of the cutting tool will also affect the chatter vibration in the milling process. In addition, the thermal load in the cutting tool edge should be able to reduce by spreading across the tool edge radius, potentially reduce the cutting temperature. This is especially important when machining a high heat resistance material such as Inconel 718. From the above discussion, variable pitch and helix cutting tools are able to mitigate the chatter vibration, and with the combination of tool edge radius, the cutting temperature reduces compare to the sharp cutting edge. The research articles related to the experimental investigations with variable pitch and variable helix angle milling cutters with tool edge radius is very limited in the literature especially in the end milling process of Inconel 718. In this paper, the variable pitch and helix end mill cutters are employed to study the effect of tool edge radius to the chatter vibration in the milling process of Inconel 718. Dynamics responses were 
recorded and analyzed during the milling process in the time domain and frequency domain to evaluate the chatter characteristic.

\section{Experimental methods and materials}

\subsection{Experiment material and cutting tools}

The work material used for the current experimental study is Inconel 718 with the dimension of $240 \times 104 \times 18$ $\mathrm{mm}(\mathrm{l} \times \mathrm{b} \times \mathrm{h})$. The composition of the work piece is listed in Table 1 .

Table 1 Inconel 718 composition

\begin{tabular}{lllllllllll}
\hline Mater & \multicolumn{8}{c}{ Chemical composition $\left(\mathrm{W}_{\mathrm{t}}\right) \%$} \\
\cline { 2 - 11 } & $\mathrm{Ni}$ & $\mathrm{C}$ & $\mathrm{Nb}$ & $\mathrm{M}$ & $\mathrm{Ti}$ & $\mathrm{C}$ & $\mathrm{Si}$ & $\mathrm{M}$ & $\mathrm{B}$ & $\mathrm{Fe}$ \\
& & $\mathrm{r}$ & & $\mathrm{o}$ & & & & $\mathrm{n}$ & & \\
\hline Incon & 51. & 1 & 5.1 & 2.9 & 1.0 & 0.0 & 0.2 & 0.0 & 0.0 & $\mathrm{La}$ \\
el 718 & 75 & 7 & 5 & 3 & 7 & 42 & 1 & 3 & 06 & $\mathrm{st}$ \\
\hline
\end{tabular}

The cutting tool used in the current experiment is a four flute solid carbide end mill with sub-micrograin size of $0.2 \mu \mathrm{m}$ and $12 \%$ cobalt contain which has high resistance to heat. The diameter of the cutting tool, (d) is $10 \mathrm{~mm}$ and the total length of the cutting tool, (L) of $72 \mathrm{~mm}$ as shown in Figure 3. The cutting tool is also chatter resistance with its unique geometry of variable helix angle $\left(35^{\circ}\right.$ and $\left.38^{\circ}\right)$ and variable pitch angle $\left(87^{\circ}\right.$, $\left.89^{\circ}, 91^{\circ}, 93^{\circ}\right)$. In addition, the cutting tool also has tool edge radius as shown in Figure 3 which is denoted as $\mathrm{R}$. Two cutting tools, namely cutting tool No.1 $(0.3 \mathrm{~mm}$ tool edge radius) and cutting tool No.2 (1.0mm tool edge radius) were used to carry out the experiment.

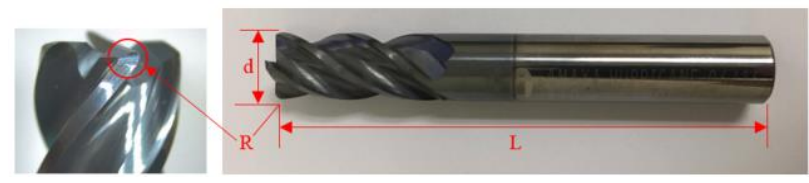

Figure 3 End mill cutters

\subsection{Experiment setup and measurement}

The experiment was performed on Leadwell V-30 vertical CNC machining center. The experiment setup can be illustrated in Figure 4. A tri-axial printed circuit board accelerometer is employed to capture the acceleration of the workpiece during the milling process. The accelerometer is adhesively mounted on top of the workpiece to sample the chatter vibration during the milling process. In order to keep the measurement consistent, the chatter vibration was sampled at the same location in every cutting pass. The chatter vibration was sampled at $2000 \mathrm{~Hz}$. The accelerometer is connected to data acquisition board (DAQ) and to the computer for data recording.

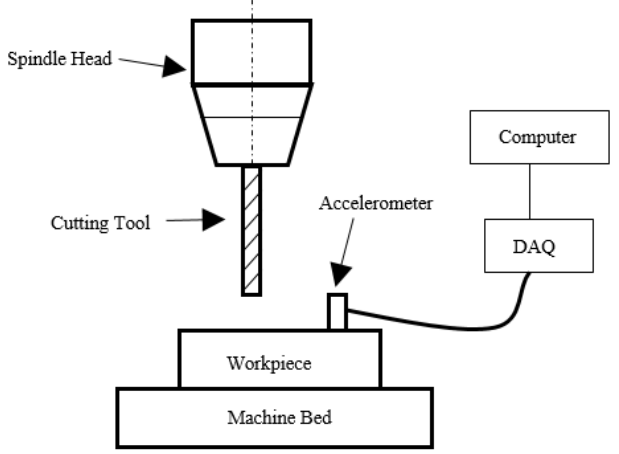

Figure 4 Experimental setup

\subsection{Experiment parameters}

The end milling process was carried out in dry condition with down milling mode. The cutting parameters for the experiments are listed in Table 2. Both cutting tool No.1 and cutting tool No.2 were utilized to perform milling process with different cutting speed.

Table 2

\begin{tabular}{lc}
\multicolumn{2}{c}{ Table 2 } \\
\hline Parameters & Value \\
\hline Cutting speed (m/min) & $31.42,62.83,94.25,125.67$ \\
Spindle Speed (RPM) & $1000,2000,3000,4000$ \\
Tool diameter (mm) & 10 \\
Axial depth of cut $(\mathrm{mm})$ & 0.1 \\
Radial depth of cut $(\mathrm{mm})$ & 3 \\
Table Feed $(\mathrm{mm} / \mathrm{min})$ & 100 \\
Tool overhang length $(\mathrm{mm})$ & 30 \\
\hline
\end{tabular}

\subsection{Modal analysis}

The frequency response function (FRF) of the machinetool setup was determined before the experiment, the purpose of finding the FRF of the machine-tool system is to ensure that the operating frequency will not trigger the resonance point of the system. The standardize procedure in obtaining the FRF of the system was carried out $[25,26]$. The impact test was carried out using a PCB352C23 medium size steel-tip impact hammer and also PCB-352C03 ceramic shear ICP accelerometer. Both of the sensor data was collected by NI-USB 9234 4-channel data acquisition module. The result of the FRF can be illustrated at Figure 5, the first and second mode of the system are $860 \mathrm{~Hz}$ and $1280 \mathrm{~Hz}$ respectively. It is also note that the maximum operating frequency for the current experiment is around $267 \mathrm{~Hz}$. Therefore, it should not trigger the resonance point of the machine-tool system. On the other hand, the workpiece-vice system is stiffer than the machine-tool system. Therefore, the FRF of the workpiece-vice system is not necessary. 


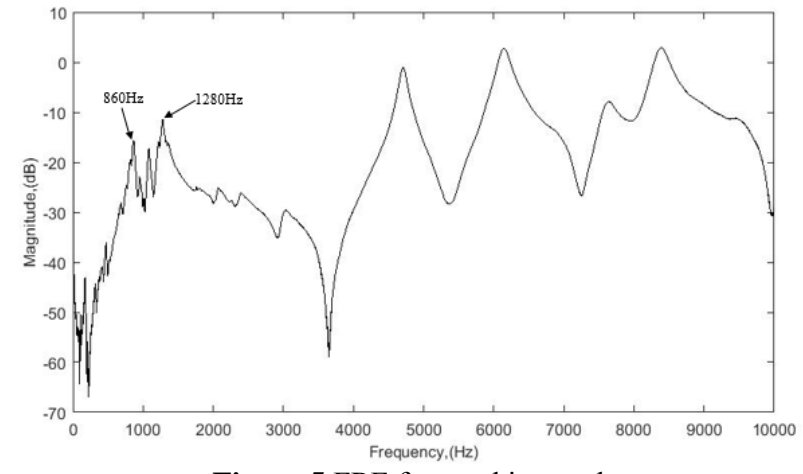

Figure 5 FRF for machine-tool

\section{Results and discussion}

\subsection{Time domain analysis}

In the milling process, the vibration in the x-axis, also known as cutting direction (illustrated at Figure 6) has dominant effect on the chatter vibration. Since the process is a down milling mode, the chip thickness is maximum upon entry and minimum at the exit. The high impact during the entry of the cutting zone is the starting point of the regenerative effect. This is the direction where the cutting tool edge exerts highest cutting force during the milling process. Figure 7 shows the typical time-domain response in the milling process of Inconel 718 at spindle speed of 1000 RPM. Based on the sampling rate and spindle speed, it can be calculated that each cutting cycle take about 120 data point at 1000 RPM. A cutting cycle is defined as one complete revolution of a cutting tool where all of the cutting edge are engaged with the work piece. The waveform shown in Figure 7 is at 1000 RPM, the waveform exhibits time periodic timevarying characteristics due to the intermittent cutting characteristic of the milling process. Also cyclic behavior of the chatter responses is observed, difference between the dynamic response for cutting tool No.1 and cutting No. 2 is not similar. Cutting tool No. 1 shows a higher tendecy of vibration as compared to Cutting tool No. 2, where the response range of cutting tool No. 1 (p-p $0.4 \mathrm{~g}$ ) is doubled of cutting tool No. 2 (p-p $0.2 \mathrm{~g}$ ). It is also demonstrated that the responses for Cutting tool No. 2 attributes less noise, indicating a cleaner cut of work piece.

Further to the dynamic responses, a root mean square (RMS) value of the dynamic response is computed to evaluate the intensity of the chatter vibration.

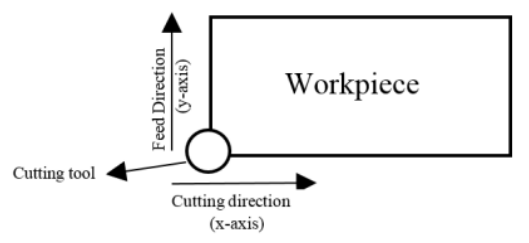

Figure 6 Cutting direction illustration

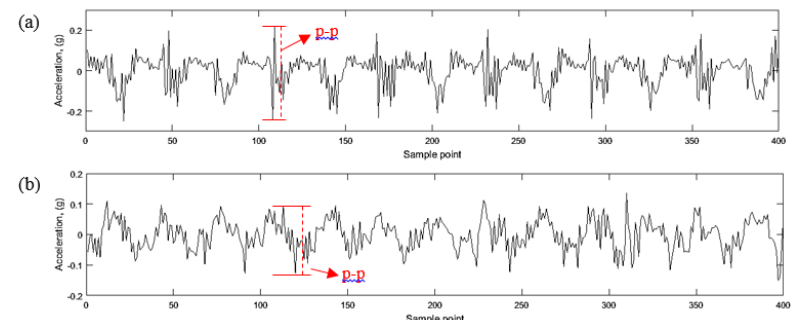

Figure 7 Time domain vibration response at 1000 RPM

(a) Cutting tool No.1 (b) Cutting tool No.2

Figure 8 shows the RMS value of cutting tool No.1 and No.2 at different spindle speeds. The results show that the RMS value for cutting tool No.1 is higher than cutting tool No.2. The lowest RMS value are located at the lowest spindle speed for both cutting tools, this is due to the damping process effect. The stability of the milling process increases at lower cutting speed, in this case, the cutting speed is around $31 \mathrm{~m} / \mathrm{s}$. Damping process phenomena has been explained by many of the researchers $[14,15]$. In addition to the process damping effect, the regenerative effect is also suppress by the unique geometry of the cutting tool (variable helix and pitch). Theoretically, the vibration could be higher with the standard end milling tool (uniform helix and pitch). In addition, it is also note that cutting tool No.1 (tool edge radius: $0.3 \mathrm{~mm}$ ) generally has higher RMS value compared to cutting tool No.2 (tool edge radius: $1 \mathrm{~mm}$ ). This is due to the ploughing force that is introduced by Albrecht [26], ploughing force is induced by the tool edge radius, and it can be considered as a frictional force that occur between the area at the flank face of the tool and the machined surface. The ploughing force increases with the increase of tool edge radius that is shown in the research work by Wyen [27], with the increase of ploughing force, it shows that the chatter vibration can be mitigated. Also the RMS acceleration amplitude is generally lower for cutting tool No.2 at most of the cutting speed except 3000 RPM. In other words, the initial guess is that the cutting tool with sharper cutting edge generate more noise, a representation of excessive vibrations and have a higher tendency to vibrate due to smaller of contact area between the flank wear and machined surface.

However, there is an exceptional at 3000 RPM, where cutting tool No.2 has higher value of RMS compare to cutting tool No.1 by around $8.8 \%$. One possible reason is the cutting process has triggers chatter frequency of the cutting tool, hence creating high vibration. Considering 3000 RPM as the resonant frequency, at 4000 RPM, the cutting frequency would have surpass its resonance hence the tendency of high vibration is reduced. On the other hand, the process damping effect also diminishes with the increase of cutting speed, and therefore higher amplitude of vibration also expected. Another possible reason that causes the sudden increase in RMS value at 3000 RPM for both of the cutting tool may be due to the presence of work-hardening phenomena during the milling process. Work-hardening increases the resistance to the cutting process and induced higher intensity of vibration. Therefore, cutting tool No.1 also experience a sudden 
increase in RMS value from cutting speed of 2000 RPM to 3000RPM. The presence of work-hardening phenomena is due to the high cutting temperature as shown in Figure 9. In addition, the cutting temperature at 4000 RPM is too high that the cutting tool No.2 merely cutting the work piece with ploughing force just like grinding through the workpiece. Since cutting tool No.2 has higher value of tool edge radius, the contact area of the flank face and the machined surface is higher, and therefore the cutting edge is worn off due to high temperature cutting at 4000RPM as shown in Figure 10. This phenomena will be discussed when the signal is analysed in frequency-domain in the next section.

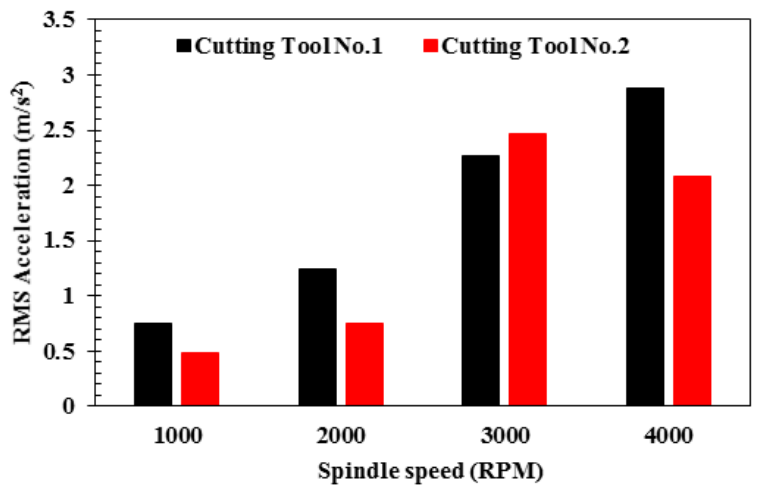

Figure 8 RMS acceleration value at various spindle speed

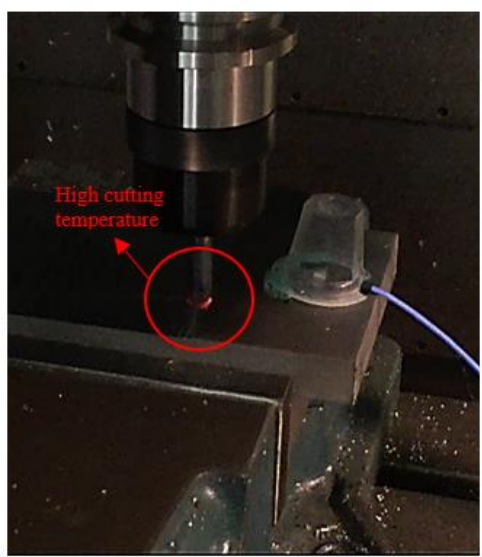

Figure 9 High cutting temperature

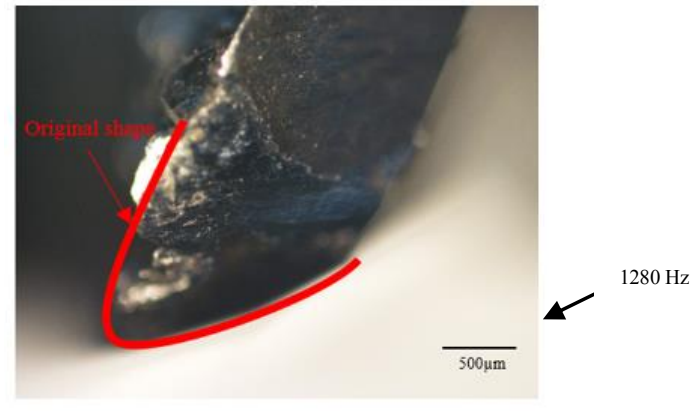

Figure 10 Worn off cutting tool

\subsection{Frequency domain analysis}

Time domain signal can be converted into frequency domain signal by using the widely used method known as Fast Fourier Transform (FFT) to find out the content of the vibration response in frequency domain. In frequency domain, the vibration response often provides interesting information or the characteristic of the response. The vibration response from the milling process can be considered periodic time-varying and hence it is reasonable to apply frequency analysis method. Therefore, in this case, Fast Fourier Transform method is employed. The frequency domain analysis will present the effect of tool edge radius to the characteristic of the vibration response. In order to eliminate the static component of the vibration response, the static component of the response is filtered off before applying Fast Fourier Transform.

Fig. 3.6 shows the frequency spectra at different cutting speed for cutting tool No.1 and cutting tool No.2. At spindle speed of 1000 RPM, cutting tool No.1 shows numerous peak in the frequency band from 0 to $200 \mathrm{~Hz}$, while for cutting tool No.2, there is a dominate peak at around $65 \mathrm{~Hz}$. Based on the spindle speed and number of flute of the cutting edge, the number of impacts during the milling process is computed at frequency of $16.67 \mathrm{~Hz}$. In other words, each of the cutting edge will hits on the workpiece for 16.67 times per second. Since the number of flutes are 4, the operating frequency is $66.68 \mathrm{~Hz}$. Other operating frequencies are $133.36 \mathrm{~Hz}$ (2000 RPM), 200.04 $\mathrm{Hz}$ (3000 RPM), and $266.72 \mathrm{~Hz}$ (4000 RPM).

Magnitude values based on the operating frequencies are evaluated. From Fig. 3.6 (a)-(d), it is observed that the magnitude are consistently lower $(<400)$ with respect to the operating frequencies. Fig. $3.6(e)-(h)$ shows otherwise, where as high magnitude $(>1000)$ is observed at the operating frequency of $200.04 \mathrm{~Hz}$. This observation coincides with the high RMS responses at 3000 RPM. The plot of FFT further justify the possibility of chatter occur at the 3000 RPM for Cutting tool No.2. However, it should be noted that as the operating frequency increases, the ploughing force also increases, and subsequently an increase in cutting temperature.

Therefore, it is deduced that with the increase of operating frequencies, an increase in the dynamic responses is expected, due to the increase of ploughing force. Unless a trigger towards the resonance frequencies is made, the dynamic responses will increase gradually as demonstrated by Cutting tool No.1. However, if the cutting operation trigger its resonance frequency, hence an extraordinary high vibration will occur at that frequency as demonstrated in Figure $3.6(\mathrm{~g})$ where a high magnitude coincides with its operating frequency. In this case, the tool edge radius is the main factor that causes the chatter vibration to occur.

On the other hand, Fig. $3.6(a)-(d)$ also shows multiple peak at beyond the operating frequency, those peak occur may be due to the excessive noise that developed by cutting tool with lower tool edge radius. This phenomena also occur in cutting tool No.2, however, the magnitude value is much smaller compare to the cutting tool No.1. Under normal milling condition, the 
magnitude value at operating frequency should be higher than the rest of the frequency band which also shown in the analysis of Huang [19]. For example, the magnitude value at operating frequency for Fig $3.6(a)$ and $(e)$ is higher than the rest of the frequency band. Therefore, it can be conclude that the milling process of cutting tool No. 2 is more stable than cutting tool No. 1 at 1000 RPM and 2000RPM with the assistance of process damping effect. However, as the cutting speed increases, the milling process of cutting tool No.2 at 4000 RPM is unstable due to higher cutting speed as mentioned in section 3.1, and multiple peak is clearly shown in Fig 3.6 (h).

(a)

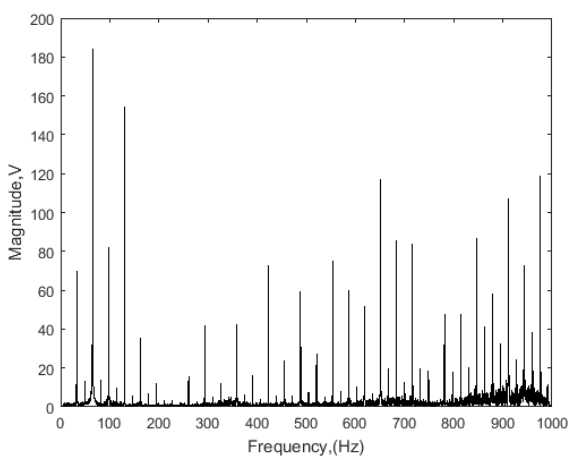

(b)

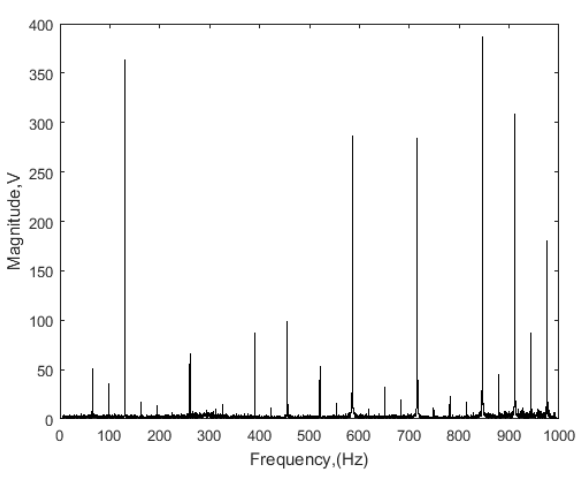

(c)

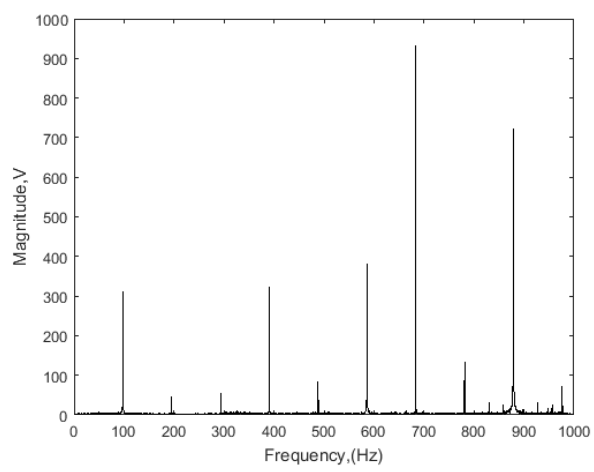

(d)

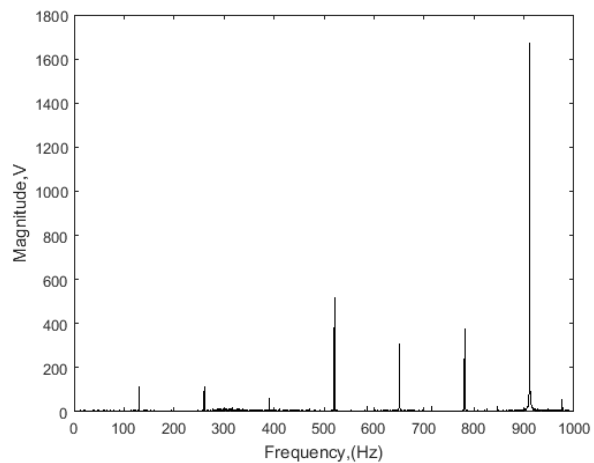

(e)

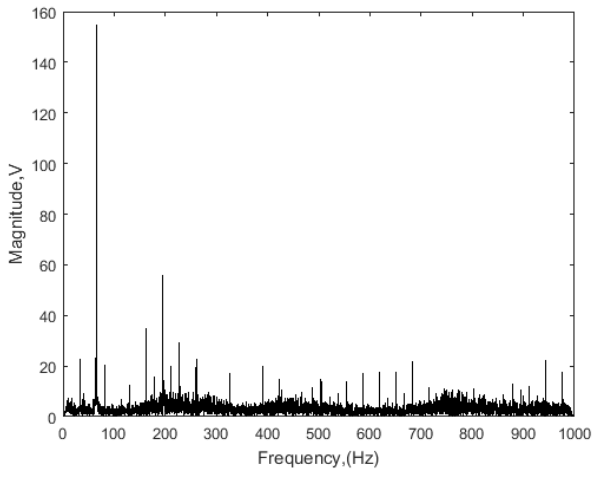

(f)

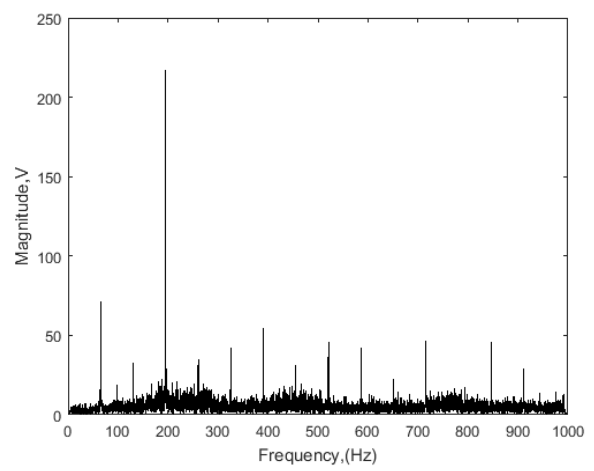

(g)

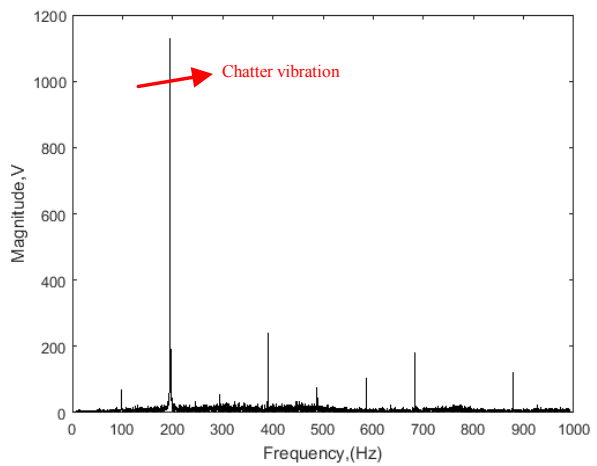

(h)

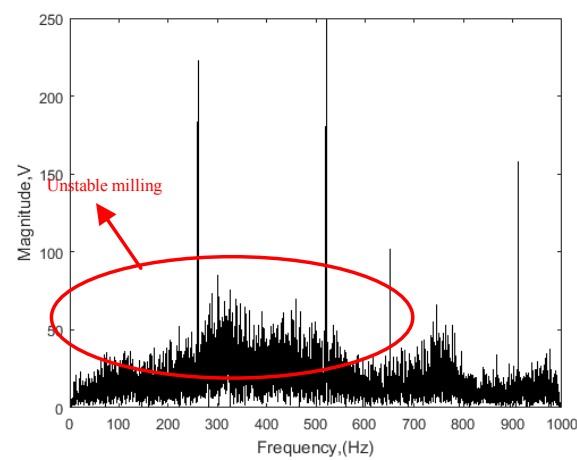

Figure 11 Frequency spectral for cutting tool No.1 (a) 1000 RPM, (b) 2000 RPM, (c) 3000 RPM, (d) 4000RPM, for cutting tool No.2 (e) 1000 RPM. (f) 2000 RPM, (g) 3000 RPM, (h) 4000 RPM

\section{Acknowledgements}

The authors are grateful to the Ministry of Higher Education (Malaysia) for providing the Fundamental Research Grant Scheme 
(FRGS/1/2014/TK01/CURTIN/02/2) for this work to be possible.

\section{References}

[1] Ezugwu, E. O. 2005. "Key Improvements in the Machining of Difficult-to-Cut Aerospace Superalloys." International Journal of Machine Tools and Manufacture 45 (12-13): 1353-1367

[2] Dudzinski, D., A. Devillez, A. Moufki, D. Larrouquère, V. Zerrouki, and J. Vigneau. 2004. "A Review of Developments Towards Dry and High Speed Machining of Inconel 718 Alloy." International Journal of Machine Tools and Manufacture 44 (4): 439-456

[3] Ulutan, Durul, and Tugrul Ozel. 2011. "Machining Induced Surface Integrity in Titanium and Nickel Alloys: A Review." International Journal of Machine Tools and Manufacture 51 (3): 250-280

[4] Fang, Ning, P. Srinivasa Pai, and S. Mosquea. "Effect of tool edge wear on the cutting forces and vibrations in high-speed finish machining of Inconel 718: an experimental study and wavelet transform analysis." The International Journal of Advanced Manufacturing Technology 52, no. 1 (2011): 65-77.

[5] Pervaiz, Salman, Amir Rashid, Ibrahim Deiab, and Mihai Nicolescu. 2014. "Influence of Tool Materials on Machinability of Titanium- and Nickel-Based Alloys: A Review." Materials and Manufacturing Processes 29 (3): 219-252

[6] Jawaid, A., S. Koksal, and S. Sharif. 2001. "Cutting Performance and Wear Characteristics of Pvd Coated and Uncoated Carbide Tools in Face Milling Inconel 718 Aerospace Alloy." Journal of Materials Processing Technology 116 (1): 2-9

[7] Zhang, S., J. F. Li, and Y. W. Wang. 2012. "Tool Life and Cutting Forces in End Milling Inconel 718 under Dry and Minimum Quantity Cooling Lubrication Cutting Conditions." Journal of Cleaner Production 32: 81-87.

[8] Hadi, M. A., J. A. Ghani, C. H. Che Haron, and M. S. Kasim. 2013. "Comparison between up-Milling and Down-Milling Operations on Tool Wear in Milling Inconel 718." Procedia Engineering 68: 647-653

[9] Zhang, S., J. F. Li, and Y. W. Wang. 2012. "Tool Life and Cutting Forces in End Milling Inconel 718 under Dry and Minimum Quantity Cooling Lubrication Cutting Conditions." Journal of Cleaner Production 32: 81-87.

[10] Taylor, Fred W. "The Art of Cutting Metals." Scientific American 63 (1907): 25942-44.

[11] Wiercigroch, Marian, and Erhan Budak. "Sources of Nonlinearities, Chatter Generation and Suppression in Metal Cutting." Philosophical Transactions of the Royal Society of London A: Mathematical, Physical and Engineering Sciences 359, no. 1781 (2001): 663-93.
[12] Altintas, Yusuf. Manufacturing Automation: Metal Cutting Mechanics, Machine Tool Vibrations, and CNC Design. Cambridge university press, 2012.

[13] Quintana, Guillem, and Joaquim Ciurana. 2011. "Chatter in Machining Processes: A Review." International Journal of Machine Tools and Manufacture 51 (5): 363-376

[14] Tobias, SA, and W Fishwick. "Theory of Regenerative Machine Tool Chatter." The engineer 205, no. 7 (1958): 199-203.

[15] Sisson, Timothy Raymond, and Richard L Kegg. "An Explanation of Low-Speed Chatter Effects." Journal of Engineering for Industry 91, no. 4 (1969): 951-58.

[16] Slavicek, Jan. 1965. "The Effect of Irregular Tooth Pitch on Stability of Milling" Proc. of the 6th Int. MTDR

[17] Shirase (1996) Cutting force and dimensional surface error generation in peripheral milling with variable pitch helical end mills. Int J Mach Tool Manuf 36(5):567-584

[18] Altıntaş, Y., S. Engin, and E. Budak. "Analytical Stability Prediction and Design of Variable Pitch Cutters." Journal of Manufacturing Science and Engineering 121, no. 2 (1999): 173-78.

[19] Huang, Panling, Jianfeng Li, Jie Sun, and Maojie Ge. 2012. "Milling Force Vibration Analysis in HighSpeed Milling Titanium Alloy Using Variable Pitch Angle Mill." The International Journal of Advanced Manufacturing

[20] Sellmeier, V, and B Denkena. "Stable Islands in the Stability Chart of Milling Processes Due to Unequal Tooth Pitch." International Journal of Machine Tools and Manufacture 51, no. 2 (2011): 152-64.

[21] Comak, Alptunc, and Erhan Budak. "Modeling Dynamics and Stability of Variable Pitch and Helix Milling Tools for Development of a Design Method to Maximize Chatter Stability." Precision Engineering 47 (2017): 459-68.

[22] Denkena, B., and D. Biermann. "Cutting Edge Geometries." CIRP Annals - Manufacturing Technology 63, no. 2 (2014): 631-53.

[23] Endres, William J., and Raja K. Kountanya. "The Effects of Corner Radius and Edge Radius on Tool Flank Wear." Journal of Manufacturing Processes 4, no. 2 (2002/01/01/ 2002): 89-96.

[24] Gurdal, Ozan, Erdem Ozturk, and Neil D. Sims. "Analysis of Process Damping in Milling." Procedia CIRP 55, no. Supplement C (2016/01/01/ 2016): $152-57$.

[25] Yusoff, AhmadR, Sam Turner, ChrisM Taylor, and NeilD Sims. "The Role of Tool Geometry in Process Damped Milling." The International Journal of Advanced Manufacturing Technology 50, no. 9-12 (2010/10/01 2010): 883-95.

[26] Albrecht, Paul. "New Developments in the Theory of the Metal-Cutting Process: Part I. The Ploughing Process in Metal Cutting." Journal of engineering for industry 82, no. 4 (1960): 348-57.

[27] Wyen, C-F, and Konrad Wegener. "Influence of Cutting Edge Radius on Cutting Forces in Machining Titanium." CIRP annals 59, no. 1 (2010): 93-96. 